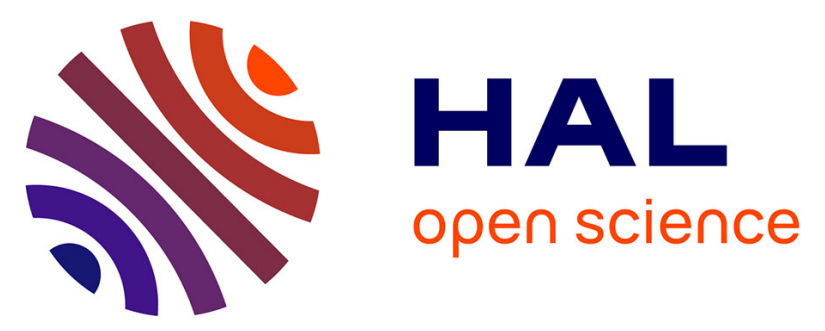

\title{
Microbiological and epidemiological investigation of the Neisseria meningitidis serogroup A epidemic in Niger in 2009: last wave before the introduction of the serogroup
} A meningococcal conjugate vaccine?

\author{
J. M. Collard, Z. Maman, A. Abani, H. B. Mainasara, S. Djibo, H. Yacouba, \\ R. Maitournam, F. Sidikou, P. Nicolas, J. Rocourt, et al.
}

\section{To cite this version:}

J. M. Collard, Z. Maman, A. Abani, H. B. Mainasara, S. Djibo, et al.. Microbiological and epidemiological investigation of the Neisseria meningitidis serogroup A epidemic in Niger in 2009: last wave before the introduction of the serogroup A meningococcal conjugate vaccine?. Epidemiology and Infection, 2011, 139 (11), pp.1656-60. 10.1017/S0950268810003092 . pasteur-00788047

\section{HAL Id: pasteur-00788047}

https://hal-riip.archives-ouvertes.fr/pasteur-00788047

Submitted on 13 Feb 2013

HAL is a multi-disciplinary open access archive for the deposit and dissemination of scientific research documents, whether they are published or not. The documents may come from teaching and research institutions in France or abroad, or from public or private research centers.
L'archive ouverte pluridisciplinaire HAL, est destinée au dépôt et à la diffusion de documents scientifiques de niveau recherche, publiés ou non, émanant des établissements d'enseignement et de recherche français ou étrangers, des laboratoires publics ou privés. 


\title{
SHORT REPORT
}

Microbiological and epidemiological investigation of the Neisseria meningitidis serogroup A epidemic in Niger in 2009: last wave before the introduction of the serogroup $A$ meningococcal conjugate vaccine?

\author{
J. M. COLLARD ${ }^{1 *}$, Z. MAMAN ${ }^{2}$, A. ABANI ${ }^{2}$, H. B. MAINASARA ${ }^{1}$, S. DJIBO ${ }^{1}$, \\ H. YACOUBA ${ }^{2}$, R. MAITOURNAM ${ }^{2}$, F. SIDIKOU ${ }^{1}$, P. NICOLAS ${ }^{3}$, J. ROCOURT \\ AND J. F. JUSOT ${ }^{1}$ \\ ${ }^{1}$ Centre de Recherche Médicale et Sanitaire (CERMES), BP 10887, Niamey, Niger \\ ${ }^{2}$ Division des Statistiques, de la Surveillance et de la Riposte aux Epidémies (DSSRE), Ministère de la Santé \\ Publique, BP 623, Niamey, Niger \\ ${ }^{3}$ Unité du méningocoque, Centre Collaborateur OMS, Institut de Recherches Biomédicales des Armées, Institut \\ de Médecine Tropicale du Service de Santé des Armées, Parc du Pharo, BP 60109, 13262 Marseille cedex 07 \\ France
}

(Accepted 12 December 2010; first published online 20 January 2011)

\section{SUMMARY}

The 2009 meningitis season in Niger was characterized by an early onset, beginning in the very first weeks of the year and peaking from the 12th to the 15th week with 5655 clinical cases over the 4 weeks. From 1 January 2009 to 28 June 2009 (week 26), a total of 13733 clinical cases of meningitis were reported to the national epidemiological surveillance system with a case-fatality rate of $4 \cdot 2 \%$. During the season 25 of the 42 health districts reached the epidemic threshold and 11 the alert threshold. Reactive mass vaccination campaigns involving a total of 5166741 doses of the polysaccharide meningococcal bivalent $(\mathrm{A}+\mathrm{C})$ vaccine progressively controlled the outbreak in most parts of the country. A total of 3755 cerebrospinal fluid samples representing $28.1 \%$ of the suspected meningitis cases were analysed. Serogroup A meningococci were the causative agent in $97.5 \%$ of the meningococcal cases. Multi-locus sequence typing of 26 meningococal serogroup A strains showed 25 sequence type (ST)7 and one ST2859, both sequence types belonging to the ST5 clonal complex (CC5) of subgroup III. This is the largest epidemic observed in Niger since those of 1995-1996 (59 948 notified cases) and 2000 (14633 notified cases).

Key words: Bacterial meningitis, epidemic, meningococcal disease, Niger.

Niger, a sub-Saharan country of $1267000 \mathrm{~km}^{2}$ with a population of about 14.8 million and centrally located in the African meningitis belt has regularly experienced meningococcal meningitis epidemics, mostly caused by serogroup A. The last major epidemic group A waves occurred in 1995 and affected 41930

\footnotetext{
* Author for correspondence: Dr J. M. Collard, 634 Boulevard de la Nation YN034, PO Box 10887, Niamey, Niger.

(Email: jmcollard@cermes.org)
}

people of whom 3639 died [case-fatality rate (CFR) $8.7 \%$ ], in 1996 with 16745 notified cases (CFR $9 \cdot 4 \%$ ), and in 2000 with 14633 cases (CFR 7.5\%). Since then, serogroup A has remained predominant although without causing large epidemics in Niger. In the first weeks of 2009, a notable increase in clinical cases was reported to the national surveillance system (DSSRE) (Fig. 1). By week 5 the suspected cases reached 1024, with 65 deaths (CFR 6.3\%) registered 


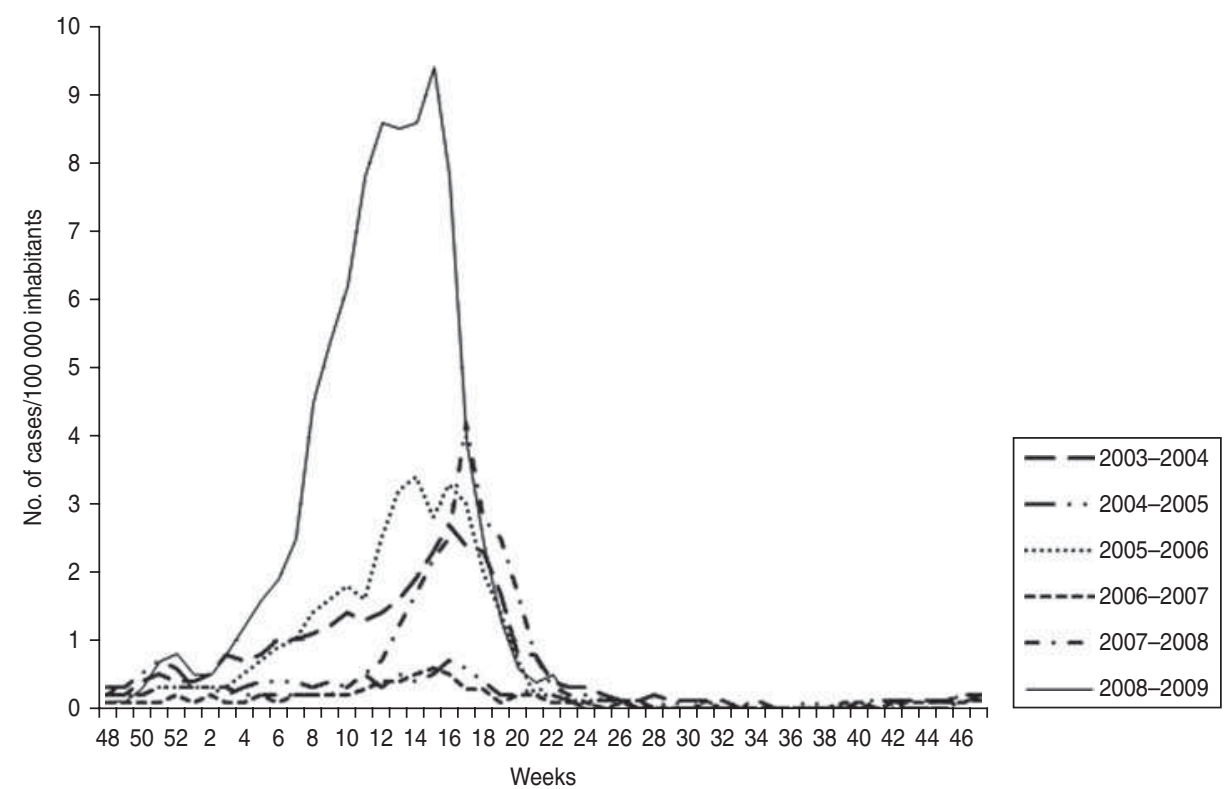

Fig. 1. Attack rates of meningitis in Niger over the years 2003-2009. (Data collected by the Direction of Statistics, Surveillance and Response to Epidemics - Ministry of Public Health.)

by the DSSRE. At that time, the health district of Gaya (southwestern part of Niger) crossed the epidemic threshold and three health districts in the Tahoua (inner part of the country) and Zinder (southeastern, on the border with Nigeria) regions crossed the alert threshold. Microbiology of CSF performed at the Centre de Recherche Medicale et Sanitaire (CERMES), which is in charge of the national microbiological surveillance, showed that Neisseria meningitidis serogroup A was the predominant causative agent (see below). Outbreaks progressed to other parts of the country; the epidemic peak was observed from the 12th to the 15th week with respectively 1338, 1364, 1432 and 1521 clinical cases. Regional attack rates varied between 8.5 and $9 \cdot 3 / 100000$ inhabitants but attack rates higher than 30 were observed at district level (Madarounfa, weeks 12-14; Boboye, week 15). By week 15, most health districts still affected by the epidemic were located in southern Niger. By week 19, the last health districts crossing the epidemic threshold were located in the extreme western (Tillabery) and eastern (Abalak) parts of the country.

In response to the serogroup A meningococcal epidemic, surveillance was rapidly strengthened and case management using standard antibiotics (oily chloramphenicol, ceftriaxone or ampicillin when available) was facilitated by free treatment of meningitis cases and pre-positioning of care materials, antibiotics and antipyretics at regional, district and healthcare facility level. Based on the serogroup determination and epidemiological surveillance, reactive mass vaccination campaigns were launched by the Ministry of Public Health (MoPH) with the support of WHO and partners, including Médecins sans Frontières and UNICEF. These were targeted not only at districts that had reached the epidemic threshold, but also in those in alert status and adjacent to an epidemic district. The population of the capital (Niamey Region) unvaccinated since 2001 was also vaccinated although these districts had not reached the alert threshold. The target population for immunization was aged 2-29 years. The stockpile at the beginning of 2009 was 822650 doses of bivalent $(\mathrm{A}+\mathrm{C})$ vaccine and complementary doses were provided by the International Coordinating Group (ICG) on Vaccine Provision for Epidemic Meningitis Control. Mass vaccinations allowed for progressive control of the outbreaks in most parts of the country. Finally 5166741 doses were administered to the whole country with vaccination coverage varying between $17 \%$ and $97 \%$ of the target population according to region (Table 1).

By week 26, when the incidence of meningitis had fallen to pre-epidemic levels, a total of 25 out of 42 health districts in Niger had reached the epidemic 
Table 1. Vaccine response to the N. meningitidis serogroup A 2009 epidemic

\begin{tabular}{|c|c|c|c|c|}
\hline Regions & $\begin{array}{l}\text { Vaccinated } \\
\text { districts }\end{array}$ & $\begin{array}{l}\text { Target } \\
\text { population } \\
(2-29 \mathrm{yr})\end{array}$ & $\begin{array}{l}\text { Vaccinated } \\
\text { population }\end{array}$ & $\begin{array}{l}\text { Coverage, mean } \\
\text { per region } \\
\text { (range according } \\
\text { to health districts) }\end{array}$ \\
\hline Agadez & $3 / 4$ & 200769 & 155675 & $77 \cdot 5 \%(62-130)$ \\
\hline Diffa & $2 / 3$ & 180889 & 43685 & $24 \cdot 2 \%(14-47)$ \\
\hline Dosso & $5 / 5$ & 381658 & 199360 & $52 \cdot 2 \%(55-82)$ \\
\hline Maradi & $6 / 7$ & 1686982 & 1167253 & $69 \cdot 2 \%(31-105)$ \\
\hline Tahoua & $4 / 8$ & 789322 & 139862 & $17 \cdot 7 \%(12-35)$ \\
\hline Tillabery & $5 / 6$ & 876055 & 185288 & $21 \cdot 2 \%(16-36)$ \\
\hline Zinder & $6 / 6$ & 1950535 & 1511579 & $77 \cdot 5 \%(52-121)$ \\
\hline Niamey & $3 / 3$ & 664164 & 646705 & $97 \cdot 4 \%(92-106)$ \\
\hline Total & $34 / 42$ & 8660303 & 5166741 & $59 \cdot 7 \%$ \\
\hline
\end{tabular}

threshold and 11 the alert threshold. Modelling of the spatial-temporal evolution of the epidemic at healthcentre level failed to show a definite progression in the dynamics of meningitis-confirmed cases (data not shown). Finally from 1 January to 28 June 2009 a total of 13357 clinical cases of meningitis were reported with a CFR of $4.2 \%$ for the country, the highest CFR (11.4\%) being observed in the Niamey Region and the lowest in Zinder Region $(2 \cdot 3 \%)$. The high CFR in Niamey could be explained by several factors, among which were a more accurate diagnosis in the hospitals of the capital with fewer patients who did not have meningitis being included in the incidence statistics, and admission to the hospitals of those at the very last stages of the disease due the hesitation of the family in view of the related costs (transport and healthcare, even if these latter cases are free during a meningitis epidemic, and for children aged $<5$ years).

During the same period, CERMES which runs the microbiological surveillance for the country received 3765 CSF specimens representing $28.1 \%$ of the notified cases whereas between 2005 and 2008 CSF testing represented $70-100 \%$ of the notified cases. Reasons to explain the reduction in collecting CSF samples during a large epidemic include: lumbar puncture needles and collecting tubes being out of stock; overburdened healthcare structures; being taken into care and treatment on the basis of clinical diagnosis; and over-notification of cases.

After culture of fresh specimens or trans-isolates $(n=123)$ and PCR (all samples) targeting the main causes of bacterial meningitis ( $N$. meningitidis, Streptococcus pneumoniae, and Haemophilus influenzae $)$ [1], $51 \cdot 5 \%(n=1939)$ of CSF specimens remained negative. Among positive CSF specimens, $N$. meningitidis was by far the most predominant ( $n=1683$ ), followed by $S$. pneumoniae with 73 cases; $H$. influenzae accounted for only 11 cases, of which seven were of type $b$.

Of 1683 confirmed meningococcal aetiologies, the most frequent was serogroup A $(n=1641,97 \cdot 5 \%)$. Serogroups W135 $(n=10)$ and $\mathrm{X}(n=15)$ accounted respectively for $0.6 \%$ and $0.9 \%$ of the meningococcal cases; a single case attributed to serogroup $\mathrm{Y}$ was detected by PCR, and the serogroup could not be identified for 16 specimens $(0 \cdot 95 \%)$.

All cultured meningococcal strains $(n=54)$ were analysed for their antibiotic susceptibility according to the recommendations from the Antibiogram Committee of the French Society for Microbiology (CA-SFM). They were susceptible to all tested antibiotics but especially to $\beta$-lactams (penicillin, amoxicillin, ceftriaxone) and chloramphenicol, supporting the appropriateness of WHO recommendations for antibiotic treatment [2].

A set $(n=26)$ of serogroup A meningococcal strains collected during four distinct field investigations in districts with epidemic (Gaya, Dosso, Maradi and Zinder which represent very distant places) or collected in the National Hospital of Niamey was selected and sent for multi-locus sequence typing (MLST) to the WHO Collaborating Center in Marseille, France. MLST indicated that all but one belonged to sequence type (ST)7. The sole strain belonging to ST2859 was isolated in Niamey, whereas ST7 strains came from the health districts of Dosso, Niamey, Maradi and Zinder. The CSF specimen positive for serogroup Y 
was also analysed and typed as ST8391 from clonal complex (CC) 167 .

In Niger, while the 1995 and 1996 major epidemics were due to serogroup A ST5, they were followed in 1999 and 2001 by outbreaks involving a mixed population of ST5 and ST7 strains, both sequence types belonging to ST5 CC5 of subgroup III. ST7, which differs from ST5 at one locus, had also been identified in Cameroon, Chad and Nigeria and has gradually replaced the ST5 initial clone in all the countries of the 'meningitis belt' [3]. By 2002, serogroup A ST7 strains had totally replaced the ST5 clone $[4,5]$. In 2003, a new variant of ST5 CC5 of subgroup III, ST2859, emerged in Burkina Faso and expanded gradually, causing epidemics in 2006 and 2007 involving more than 19000 and 30000 clinical cases, respectively [6]. In Niger in 2007, sequence typing performed on 17 serogroup A strains showed 11 ST7 and six ST2859. Up to 2007 no isolate of ST2859 meningococcus had been reported in Niger, and interestingly, all of the ST2859 strains were detected in the southwest of Niger bordering Burkina Faso (five strains from Tillabery Region and one from the capital Niamey); whereas all of the ST7 strains were isolated in the southeast of the country, with the exception of one strain isolated in Niamey [7]. In 2009, most meningococcal strains analysed by MLST belonged to ST7 indicating that ST7 strains remained predominant in Niger whereas they were replaced by ST2859 in Burkina Faso. This close microbiological surveillance is therefore crucial to better understand the epidemiology of meningococcal meningitis in Africa and to monitor the spread and evolution of the more virulent sequence types.

Concomitantly with the epidemic in Niger in 2009, Nigeria, which shares its northern border with Niger, also experienced an unprecedented epidemic which started in the northwestern part of the country and spread eastwards to the northeastern part of the country [8]. At week 25 (21 June), 55739 suspected cases of meningococcal disease, including 2448 deaths (CFR 4.4\%) were reported by the MoPH [9]. Nevertheless, N. meningitidis serogroup A was less prominent than in Niger $(88 \%)$. CSF specimens positive for $N$. meningitidis serogroup W135 were also found in $12 \%$ of the reported cases. In Chad, another neighbouring country (eastern border), the MoPH reported from 29 December 2008 to 21 June 2009 1329 suspected cases of meningococcal disease including 142 deaths (CFR 10.7\%) [9]. Of 288 collected CSF specimens, 58 were positive for $N$. meningitidis serogroup W135 and 45 specimens positive for $N$. meningitidis serogroup A, suggesting that both serogroups were responsible for the epidemic in Chad. On the other hand, Burkina Faso, sharing its eastern border with Niger, declared up to week 25, 4013 suspected cases of meningococcal disease, including 514 deaths (CFR 12.8\%) [9]. The laboratory results on $275 \mathrm{CSF}$ specimens indicated 78 S. pneumoniae, $36 N$. meningitidis serogroup A and three $N$. meningitidis serogroup $\mathrm{W} 135$ - the remaining specimens tested negative.

Reasons for the higher CFR in Chad remained unclear but the presence $(56 \%)$ of $N$. meningitidis serogroup W135 [8] could be one of several factors. In Burkina Faso, the higher CFR is probably due to the presence of $S$. pneumoniae as the main aetiological agent, which is known to cause a much higher mortality [10]. The biological results from these three neighbouring countries showed proportions of aetiological agents different from Niger, where the main agent identified in CSF was $N$. meningitidis serogroup A (97.5\% of meningococcal meningitis). Very few $N$. meningitidis of serogroups $\mathrm{X}$ and $\mathrm{W} 135$ were found during the course of the epidemic and S. pneumoniae was identified in only $4 \%$ of positive CSF specimens. Finally, Nigeria and Niger were the most affected countries in West Africa during the 2009 season, together accounting for more than $85 \%$ of the cases $[8,9]$.

These epidemics occurred just before the introduction of a new group A conjugate vaccine (Meningitis Vaccine Project) in the countries of the African meningitis belt. This new vaccine (MenAfriVac) has been shown to be more efficacious than the current polysaccharide vaccines during clinical trials, particularly in infants [11]. It induces protection of longer duration and (hopefully) is thought to reduce nasopharyngeal carriage as experienced by the introduction of monovalent MenC conjugate vaccine in the UK [12]. Mass vaccination campaigns with this vaccine started in September 2010 in Niger, as well as in Burkina Faso and Mali and will take place in four consecutive waves until November 2011. However, due to the relatively high vaccine coverage obtained in five of the eight regions in 2009 (except in the Diffa, Dosso and Tahoua regions, Table 1) and speculating on the spacing between major waves of meningitis epidemics in Africa, one can hope that the 2009 epidemic will be the last epidemic wave of $N$. meningitidis serogroup A in Niger before the introduction of the new conjugate vaccine. 


\section{ACKNOWLEDGEMENTS}

This work was financially supported by French Ministry of Foreign Affairs (FSP no. 2005-174) and by Sanofi Pasteur (contract Men07).

The authors are indebted to all the doctors and health staff who have sent CSF specimens and epidemiological forms to CERMES and also to the DSSRE staff. We thank Bassira Issaka, Lagaré Adamou, Amadou Moussa, Djibir Zanguina, Sani Ousmane, Issaka Seyni, Moumouni Ousseini and Adama Moussa for technical support, Noémie Phulpin, Ramatou Yahaya, Ali Sidiki and Florian Girond for database management and Amina Amadou and Ali Elhaj Mahamane for RDT production, distribution and training. We also thank the staff of WHOCC IMTSSA (Marseille, France) for MLST typing of meningococci strains. Thanks are also due to Professor Musa Hassan King for reading and commenting the manuscript.

\section{DECLARATION OF INTEREST}

None.

\section{REFERENCES}

1. Chanteau S, et al. Scaling up of PCR-based surveillance of bacterial meningitis in the African meningitis belt: indisputable benefits of multiplex PCR assay in Niger. Transactions of the Royal Society of Tropical Medicine and Hygiene 2006; 100: 677-680.

2. WHO. Control of epidemic meningococcal disease. WHO practical guidelines, 2nd edn. WHO/EMC/
BAC/98.3:1. Geneva: World Health Organization, 1998.

3. Nicolas P, et al. Clonal expansion of sequence type (ST-)5 and emergence of ST-7 in serogroup A meningococci, Africa. Emerging Infections and Diseases 2001; 7: 849-854.

4. Caughant DA, Nicolas P. Molecular surveillance of meningococcal meningitis in Africa. Vaccine 2007; 25 (Suppl. 1): A8-11.

5. Nicolas P, et al. Molecular epidemiology of Neisseria meningitidis isolated in the African meningitis belt between 1988 and 2003 shows dominance of sequence type 5 (ST-5) and ST-11 complexes. Journal of Clinical Microbiology 2005; 43: 5129-5135.

6. Teyssou R, Muros-Le Rouzic E. Meningitis epidemics in Africa: a brief overview. Vaccine 2007; 25 (Suppl. 1): A3-7.

7. Nicolas P, et al. Activity report 2008. Meningococcal Unit, WHO Collaborating Centre, Marseille, France, 2009, 23 pp.

8. World Health Organization. Meningitis in Chad, Niger and Nigeria: 2009 epidemic season. Weekly Epidemiological Record 2010; 85: 47-63.

9. Anon. Epidemiological situation of week 25 (15-21 June 2009). MDSC Meningitis Weekly Bulletin 2009 (http://www.who.int/csr/disease/meningococcal/ BulletinMeningite2009_S25.pdf) Accessed 26 August 2009

10. Yaro S, et al. Epidemiological and molecular characteristics of a highly lethal pneumococcal meningitis epidemic in Burkina Faso. Clinical Infectious Diseases 2006; 43: 693-700.

11. LaForce MF, et al. Epidemic meningitis due to Group A Neisseria meningitidis in the African meningitis belt: a persistent problem with an imminent solution. Vaccine 2009; 27 (Suppl. 2): B13-19.

12. Campbell $\mathbf{H}$, et al. Meningococcal $\mathrm{C}$ conjugate vaccine: the experience in England and Wales. Vaccine 2009; 27 (Suppl. 2): B20-29. 